\section{Normal pressure hydrocephalus after gamma knife radiosurgery in a patient with vestibular schwannoma}

Yoonah Park, MD; Bong-Goo Yoo, MD, PhD; Seonghun Jeong, MD; Won Gu Lee, MD; Meyung Kug Kim, MD, PhD; So-Young Huh, MD; Jin-Hyung Lee, MD

Department of Neurology, Kosin University College of Medicine, Busan, Republic of Korea

\section{Journal of Neurocritical \\ CASE REPORT \\ Received: July 6, 2020 \\ Revised: August 19, 2020 \\ Accepted: September 6, 2020 \\ Corresponding Author: \\ Bong Goo Yoo, MD \\ Department of Neurology, Kosin \\ University College of Medicine, 262 \\ Gamcheon-ro, Seo-gu, Busan 49267, \\ Korea \\ Tel: +82-51-990-6461 \\ Fax: +82-51-990-3077 \\ E-mail:ybg99@naver.com}

Background: Vestibular schwannoma is a benign, usually slow-growing tumor, which develops from Schwann cells of the eighth cranial nerve.

Case Report: The treatment options for the schwannoma are surgical removal or gamma knife radiosurgery. The treatment of choice depends on the size of the tumor and the level of hearing in the affected ear. After gamma knife radiosurgery, there may be some neurological complications including headache, dizziness, motor or cranial nerve deficits, seizure, carotid artery stenosis, and increased intracranial pressure. Hydrocephalus is a rare complication of gamma knife radiosurgery for vestibular schwannoma.

Conclusion: Here, we report a case of normal pressure hydrocephalus after gamma knife radiosurgery in a patient with vestibular schwannoma.

Keywords: Acoustic neuroma; Radiosurgery; Gait disturbance

\section{INTRODUCTION}

Vestibular schwannoma (VS) is a benign tumor that grows in Schwann cells of the eighth cranial nerve, and it can be treated by surgical removal or stereotactic radiosurgery including gamma knife surgery. Stereotactic radiosurgery for VS was first attempted in 1969 and has been one of the most active treatments in the last 40 years. The main side effects include facial paralysis, hearing loss, trigeminal neuralgia, and hemifacial spasm [1]. In addition, hydrocephalus is a potential concomitant disease [2-4]. In this article, we report a case of normal pressure hydrocephalus (NPH) in VS that has undergone gamma knife radiosurgery.

\section{CASE REPORT}

A 67-year-old woman visited the clinic with hearing loss in the left ear. The symptom began 1 month previously. She did not have a specific medical history, except for myasthenia gravis. Vital signs were within normal ranges. Rinne test was normal on both sides. However, the Weber test detected sensorineural hearing loss on the left side. No other abnormalities were observed during other neurological examinations. Magnetic resonance imaging revealed 

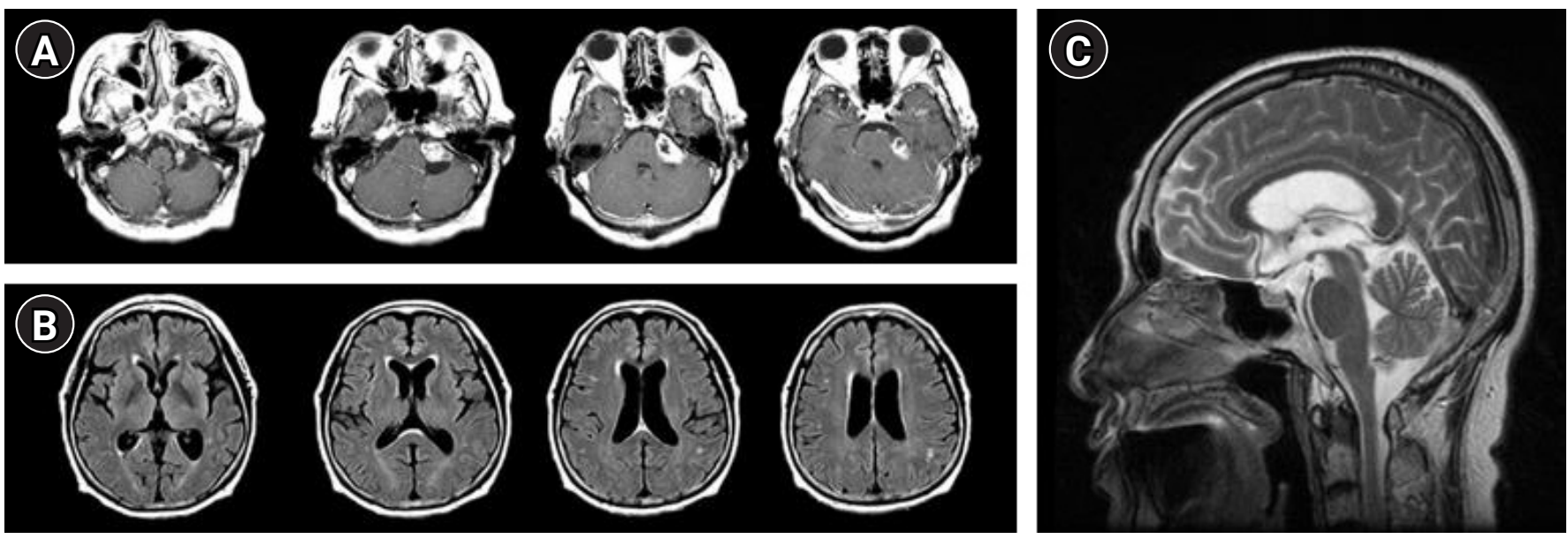

Fig. 1. (A) T1-enhanced images show a mass in the left cerebellopontine angle. (B) Fluid-attenuated inversion recovery images reveal a normal-sized ventricle. (C) T1 midsagittal view does not show any evidence of non-communicating hydrocephalus.

a high signal intensity mass measuring $2.7 \mathrm{~cm} \times 3.0 \mathrm{~cm}$ with fine enhancement on the left cerebellopontine angle (Fig. 1). This lesion was diagnosed as VS, and gamma knife surgery was performed.

Three months after, the patient visited the clinic again, complaining of progressive cognitive decline, gait disturbance, and urinary incontinence. Neurologic examination revealed normal cranial nerve functions. Motor and sensory functions were intact. Finger-to-nose and heel-to-shin tests were normal. However, she had a magnetic gait with a wide base. Additionally, she kept on losing her balance as she walked. The Timed Up and Go test was measured at 26 seconds. The patient had 2 years of education. Her Korean Mini-Mental Status Examination (K-MMSE) score was 17/30. Moreover, Seoul Neuropsychological Screening Battery (SNSB) showed impaired attention, verbal and visual memory, and executive function (Table 1).

On follow-up computed tomography (CT) scan, the size of the VS decreased from $2.7 \mathrm{~cm} \times 3.0 \mathrm{~cm}$ to $1.6 \mathrm{~cm} \times 2.8 \mathrm{~cm}$, reducing the mass effect to the surrounding brain stem. However, newly developed bilateral ventricular dilatation was observed (Fig. 2). The Evans ratio was 0.37. Cerebrospinal fluid (CSF) drainage was performed, and the pressure was measured at $10 \mathrm{~cm} \mathrm{H}_{2} \mathrm{O}$. Leukocyte count was $0 / \mathrm{mm}^{3}$, erythrocyte count was $0 / \mathrm{mm}^{3}$, protein concentration was $58 \mathrm{mg} / \mathrm{dL}$, and sugar level was $88 \mathrm{mg} / \mathrm{dL}$ (blood sugar, $97 \mathrm{mg} / \mathrm{dL}$ ), demonstrating mild increases in protein level. After CSF drainage, the patient's gait and urinary incontinence improved. The Timed Up and Go test was measured again, and the result decreased from 26 to 22 seconds. A ventriculoperitoneal shunt was inserted, resulting in subjective improvements in the gait disturbance. Her follow-up K-MMSE score improved to 22, and visual memory and executive function in the SNSB, performed after 3 months, also improved (Table 1). Another CT scan was conducted, and it revealed that the size of the ventricle had decreased, and the Evans ratio measured 0.21 (Fig. 2).

\section{DISCUSSION}

Hydrocephalus has been reported repeatedly in patients with VS who undergo gamma knife radiosurgery [1-5]. A causal relationship, however, has not been identified, and the mechanism remains unclear. The most likely hypothesis for the relationship between gamma knife radiosurgery and hydrocephalus involves tumor necrosis, which causes the protein to deposit in arachnoid granulation and interfere with CSF absorption [3]. In this case, the level of protein was slightly increased, supporting this hypothesis. In addition, fourth ventricle compression [6] or CSF flow alteration in basilar cisterns [7] is considered to be another potential mechanism. However, whether these side effects occur only in radiosurgery, including gamma knife, is still controversial $[8,9]$.

According to a 2012 study [9], 19.9\% of patients who underwent gamma knife surgery were diagnosed with hydrocephalus. However, $12.8 \%$ were diagnosed before gamma knife surgery and $7.6 \%$ occurred after surgery. In the same study, there was a statistically significant risk of the development of hydrocephalus, especially in patients with large tumor masses or who are female. With this in mind, the patient in this case was diagnosed with newly developed NPH, characterized by the traditional triad of gradual memory loss, gait disturbance, and urinary incontinence 3 months after gamma knife surgery. The causal relationship between NPH and gamma knife radiosurgery is further supported by the patient's symptom recovery with the insertion of a ventricular abdominal shunt. 
Table 1. Results of the neuropsychological test (SNSB) of pre- and post-ventriculoperitoneal shunt

\begin{tabular}{|c|c|c|c|c|}
\hline \multirow{2}{*}{ Variable } & \multicolumn{2}{|c|}{ Preoperative } & \multicolumn{2}{|c|}{ Postoperative } \\
\hline & Raw score & \%Score & Raw score & $\%$ Score \\
\hline K-MMSE & 17 & 0.27 & 23 & 0.15 \\
\hline \multicolumn{5}{|l|}{ Digit span } \\
\hline Forward & 4 & 26.11 & 4 & 26.11 \\
\hline Backward & 0 & 0.01 & 2 & 11.51 \\
\hline K-BNT & 24 & 0.4 & 25 & 0.71 \\
\hline \multicolumn{5}{|l|}{ RCF } \\
\hline Copy & 1 & 0.01 & 18 & 10.56 \\
\hline Immediate recall & NA & NA & 0.5 & 5.48 \\
\hline 20-Minute-delayed recall & NA & NA & 0 & 3.92 \\
\hline Recognition & 13 & 0.82 & 15 & 5.94 \\
\hline \multicolumn{5}{|l|}{ SVLT } \\
\hline Immediate recall & 11 & 12.51 & 12 & 17.88 \\
\hline 20-Minute-delayed recall & 0 & 0.15 & 2 & 3.14 \\
\hline Recognition & 13 & 0.06 & 17 & 9.01 \\
\hline \multicolumn{5}{|l|}{ Frontal/executive function } \\
\hline Contrast program & 6 & $<16$ & 17 & $<16$ \\
\hline Go-no-go test & 3 & $<16$ & 14 & $>16$ \\
\hline Fist-edge-palm test & Abnormal & & Abnormal & \\
\hline Alternating hand movement & Abnormal & & Normal & \\
\hline Alternating square and triangle & Preservation & & Preservation & \\
\hline Luria loop & Preservation & & Preservation & \\
\hline \multicolumn{5}{|l|}{ COWAT } \\
\hline Animal & 5 & 0.37 & 13 & 33 \\
\hline Supermarket & 3 & 0.26 & 9 & 6.55 \\
\hline$\neg$ & 0 & 1.25 & 0 & 1.25 \\
\hline O & 0 & 5.59 & 1 & 13.35 \\
\hline 人 & 0 & 4.27 & 0 & 4.27 \\
\hline Phonemic total score & 0 & 1.13 & 1 & 1.79 \\
\hline \multicolumn{5}{|l|}{ K-CWST } \\
\hline Word reading: number of correct response & 45 & $<16$ & 59 & $<16$ \\
\hline Word reading: number of error & 8 & $<16$ & 4 & $<16$ \\
\hline Word reading: response time & 120 & & 120 & \\
\hline Color reading: number of correct response & 10 & 0.01 & 25 & 0.18 \\
\hline Color reading: number of error & 28 & 0.01 & 19 & 0.01 \\
\hline Color reading: response time (sec) & 120 & & 120 & \\
\hline \multicolumn{5}{|l|}{$\mathrm{CDR}$} \\
\hline Score & 1 & & 0.5 & \\
\hline Sum of boxes & 5 & & 2 & \\
\hline GDS & NA & & 2 & \\
\hline$B-A D L$ & 13 & & 19 & \\
\hline
\end{tabular}

SNSB, Seoul Neuropsychological Screening Battery; K-MMSE, Korean Mini-Mental Status Examination; K-BNT, Korean-Boston Naming Test; RCF, Rey Complex Figure Test; NA, not applicable; SVLT, Seoul Verbal Learning Test; COWAT, Controlled Oral Word Association Test; K-CWST, Korean-Color Word Stroop Test; CDR, Clinical Dementia Rating; GDS, Global deterioration scale; B-ADL, Basic Activity of Daily Living.

As mentioned above, there have been several reported cases of hydrocephalus developing after radiosurgery for VS. However, in this case, the patient complained of a sudden decline in cognitive function, gait disturbance, and urinary frequency after gamma knife surgery, and the recovery of cognitive function after the shunt operation was confirmed through subjective reports by patients and guardians, as well as objective neuropsychiatric tests. This case is meaningful in emphasizing that neurologists should 

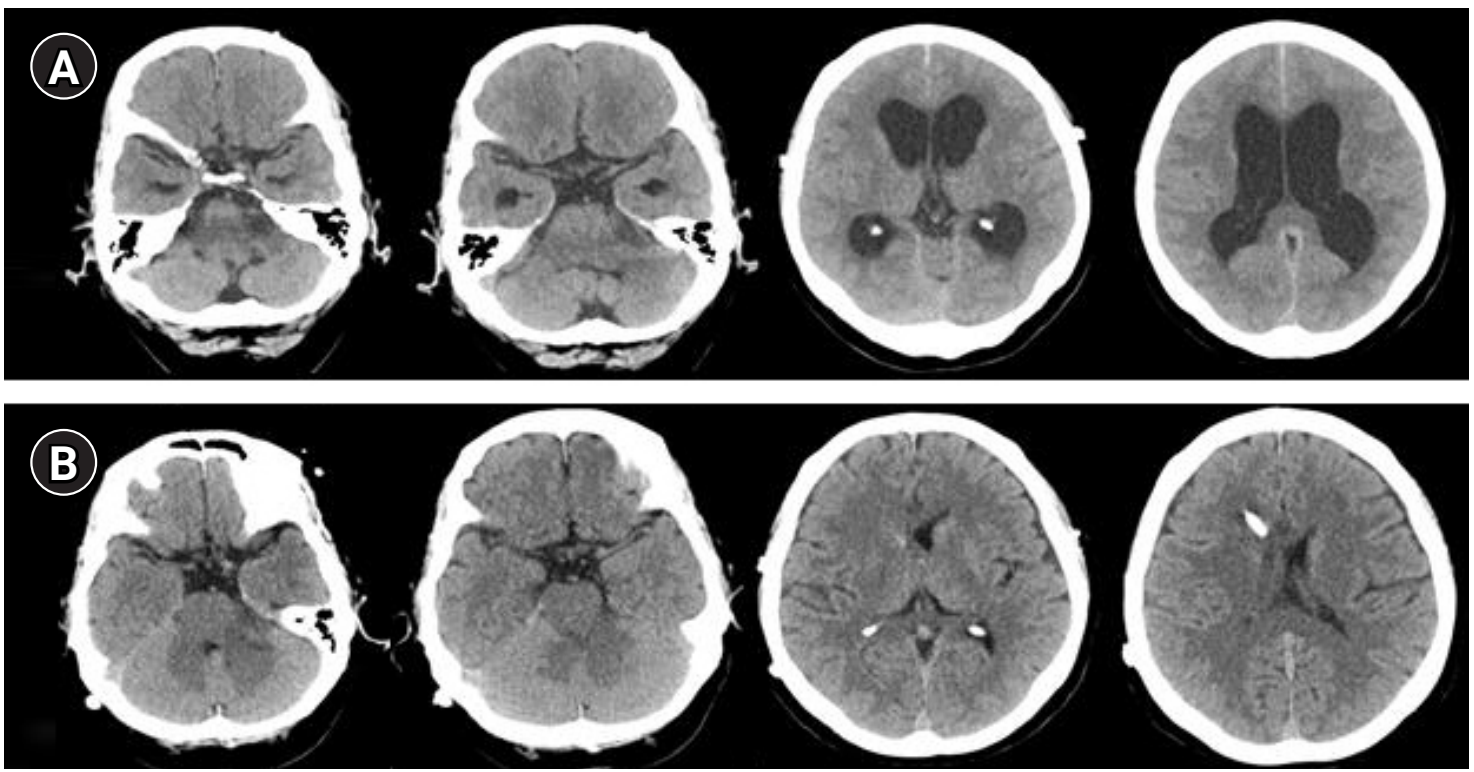

Fig. 2. Non-contrast computed tomography (CT) images of the patient. (A) Three months after gamma knife surgery, follow-up CT scans revealed enlarged ventricles. (B) After ventriculoperitoneal shunt insertion, the size of the ventricles normalized.

actively discriminate and exclude secondary correctable causes, such as NPH, when rapid progressive cognitive decline and gait disturbances occur in patients with a history of brain radiosurgery, especially considering its reversibility.

\section{ARTICLE INFORMATION}

\section{Ethics statement}

The requirements for approval of the Institutional Review Board and informed consent were waived due to the retrospective nature of this study.

\section{Conflict of interest}

No potential conflict of interest relevant to this article.

\section{Author contributions}

Concepualization: BGY. Project administration: SJ. Visualization: JHL. Writing-origicnal draft: YAP. Writing-review \& editing: MKK, SYH, WGL.

\section{ORCID}

Yoonah Park

Bong-Goo Yoo

Seonghun Jeong

Won Gu Lee

Meyung Kug Kim

So-Young Huh

Jin-Hyung Lee https://orcid.org/0000-0003-3930-3319 https://orcid.org/0000-0001-8813-7543 https://orcid.org/0000-0003-0971-1434 https://orcid.org/0000-0002-1341-8743 https://orcid.org/0000-0003-2039-6797 https://orcid.org/0000-0002-3309-6155 https://orcid.org/0000-0003-2714-3266

\section{REFERENCES}

1. Hasegawa T, Kida Y, Kato T, Lizuka H, Kuramitsu S, Yamamoto T. Long-term safety and efficacy of stereotactic radiosurgery for vestibular schwannomas: evaluation of 440 patients more than 10 years after treatment with Gamma Knife surgery. J Neurosurg 2013;118:557-65.

2. Cauley KA, Ratkovits B, Braff SP, Linnell G. Communicating hydrocephalus after gamma knife radiosurgery for vestibular schwannoma: an MR imaging study. AJNR Am J Neuroradiol 2009;30:992-4.

3. Bloch J, Vernet O, Aubé M, Villemure JG. Non-obstructive hydrocephalus associated with intracranial schwannomas: hyperproteinorrhachia as an etiopathological factor? Acta Neurochir (Wien) 2003;145:73-8.

4. Rogg JM, Ahn SH, Tung GA, Reinert SE, Norén G. Prevalence of hydrocephalus in 157 patients with vestibular schwannoma. Neuroradiology 2005;47:344-51.

5. Norén G. Long-term complications following gamma knife radiosurgery of vestibular schwannomas. Stereotact Funct Neurosurg 1998;70 Suppl 1:65-73.

6. Briggs RJ, Shelton C, Kwartler JA, Hitselberger W. Management of hydrocephalus resulting from acoustic neuromas. Otolaryngol Head Neck Surg 1993;109:1020-4.

7. Steenerson RL, Payne N. Hydrocephalus in the patient with acoustic neuroma. Otolaryngol Head Neck Surg 1992;107:359.

8. Jeon CJ, Kong DS, Nam DH, Lee JI, Park K, Kim JH. Commu- 
nicating hydrocephalus associated with surgery or radiosurgery for vestibular schwannoma.J Clin Neurosci 2010;17:862-4.

9. Lee SH, Seol HJ, Kong DS, Nam DH, Park K, Kim JH, et al.
Risk factors and tumor response associated with hydrocephalus after gamma knife radiosurgery for vestibular schwannoma. Acta Neurochir (Wien) 2012;154:1679-84. 